\title{
DOS SUGERENCIAS (MUY MENORES) SOBRE EL CONCEPTO DE TOLERANCIA
}

\author{
Manuel Atienza \\ Universidad de Alicante
}

RESUMEN. El autor discute dos aspectos de la concepción que sobre la tolerancia ha defendido Ernesto Garzón Valdés en diversos trabajos: su afirmación de que «la tolerancia es una propiedad disposicional»; y la idea de que «la tolerancia no es nunca algo intra, sino que siempre es algo intersistemático».

Palabras claves: Ernesto Garzón Valdés, tolerancia.

ABSTRACT. In this paper, two aspects of Ernesto Garzón Valdés's conception of tolerance are under discussion: his thesis on «tolerance as a dispositional property»; and the consideration according to which «tolerance is never something intra but always something inter systematic».

Keywords. Ernesto Garzón Valdés, tolerance. 
Hace algunos años, en 1992, escribí un breve trabajo sobre la filosofía práctica de Ernesto dirigido a presentar su filosofía moral como un sistema compuesto de 10 principios, 26 reglas y 28 tesis (tesis conceptuales). En su conjunto, me parecía que configuraba una respuesta práctica y una justificación racional a 10 preguntas fundamentales de la ética.

El segundo de aquellos principios era el de tolerancia que Ernesto venía a considerar como la respuesta (la respuesta moral) a esta cuestión: ¿Hasta qué punto está justificado que impongamos nuestras propias normas de vida a los demás? ¿Cuáles son los actos de los otros que atentan contra esas normas y que, sin embargo, debemos tolerar, esto es, no prohibir? El Principio de la tolerancia se formulaba así:

P2. «Nadie tiene derecho a prohibir acciones de los demás por la simple razón de que vayan en contra de alguna de las normas de su sistema normativo básico».

Y las reglas para la aplicación de este principio eran:

R5: «Todo individuo con competencia para prohibir una acción que atente contra una de las normas de su sistema normativo básico tiene la obligación de efectuar una deliberación para ver si la prohibición puede ser dejada sin efecto».

R6: «Todo individuo enfrentado a la anterior situación tiene la obligación de ser tolerante si encuentra una buena razón para ello, es decir, si: a) su sistema normativo básico no sufre un grave daño y/o b) existe una razón de su sistema normativo justificante que debe prevalecer».

R7: «Nadie puede ser tolerante con respecto a acciones moralmente prohibidas».

Las tesis conceptuales propuestas serían estas:

T4: «El sistema justificante último de cualquier individuo es su sistema ético».

T5: «La justificación de la tolerancia en el plano interpersonal implica que la democracia, en cuanto institucionalización de la tolerancia recíproca, es el único sistema político que puede aspirar a ser legítimo».

T6: «Los límites para la tolerancia en el plano personal valen, mutatis mutandis, para el plano de la política».

2. He vuelto a leer ahora, con ocasión de esta Ernestiada (tomo la expresión — que me parece afortunada - de Pierluigi CHIASSONI), el artículo de Ernesto sobre la tolerancia en que se basaba mi intento de construir el sistema EGV y he leído también sus posteriores trabajos sobre la tolerancia. en los que no me parece advertir ninguna modificación relevante con respecto al primero. No tengo realmente ninguna objeción que hacer con respecto a las tesis de fondo que Ernesto sostiene. Pero creo que hay en los mismos algunas imprecisiones o dificultades que tal vez podrían evitarse introduciendo algunos mínimos cambios conceptuales.

Aunque lo que voy a proponer pueda verse como una enorme simplificación (y, de hecho, lo es), yo diría que los problemas del texto de Ernesto vienen fundamentalmente de:

1. La afirmación de que «la tolerancia es una propiedad disposicional». 
2. La idea de que «la tolerancia no es nunca algo intra, sino que siempre es algo intersistemático».

No pretendo decir que estas dos últimas afirmaciones sean falsas, sino que pueden clarificarse (y evitarse algunas consecuencias indeseables que se derivan de ellas) si:

Ad 1) Se traza una distinción más explícita (más de lo que puede encontrarse en el texto de Ernesto) entre:

a) la tolerancia como una virtud, como - en efecto- una actitud disposicional atribuida a algunos agentes; todas las virtudes son rasgos disposicionales de carácter que mueven a la gente a actuar de una cierta manera, y

b) la tolerancia como la propiedad de un acto, una norma o un sistema.

Una consecuencia importante de la distinción puede ser el reconocimiento de que la moral (y la teoría moral) está conectada no sólo con la cuestión de qué debe uno hacer, sino también con la de qué tipo de persona debe ser uno.

Ad 2) Se especifica que un sistema normativo no es (o no es necesariamente) un conjunto de reglas, sino un conjunto de reglas y principios. En otras palabras, que algunas de las normas de un sistema normativo son normas derrotables. La idea de que una acción p está prima facie prohibida pero, consideradas todas las cosas, permitida no es una imposibilidad conceptual, una contradicción deóntica y, en consecuencia, la tolerancia puede ser considerada como algo intrasistemático. 